\title{
Label-Free Multiphoton Microscopy for the Detection and Monitoring of Calcific Aortic Valve Disease
}

\author{
Ishita Tandon, Kyle P. Quinn and Kartik Balachandran* \\ Department of Biomedical Engineering, University of Arkansas, Fayetteville, AR, United States
}

Calcific aortic valve disease (CAVD) is the most common valvular heart disease. CAVD results in a considerable socio-economic burden, especially considering the aging population in Europe and North America. The only treatment standard is surgical valve replacement as early diagnostic, mitigation, and drug strategies remain underdeveloped. Novel diagnostic techniques and biomarkers for early detection and monitoring of CAVD progression are thus a pressing need. Additionally, non-destructive tools are required for longitudinal in vitro and in vivo assessment of CAVD initiation and progression that can be translated into clinical practice in the future. Multiphoton microscopy (MPM) facilitates

OPEN ACCESS

Edited by:

Katherine Yutzey,

Cincinnati Children's Hospital Medical

Center, United States

Reviewed by:

Laura lop,

University of Padua, Italy

Adrien Lupieri,

Brigham and Women's Hospital and Harvard Medical School,

United States

*Correspondence: Kartik Balachandran kbalacha@uark.edu

Specialty section:

This article was submitted to

Heart Valve Disease,

a section of the journal

Frontiers in Cardiovascular Medicine

Received: 31 March 2021

Accepted: 17 May 2021

Published: 11 June 2021

Citation:

Tandon I, Quinn KP and

Balachandran K (2021) Label-Free Multiphoton Microscopy for the Detection and Monitoring of Calcific Aortic Valve Disease. Front. Cardiovasc. Med. 8:688513.

doi: 10.3389/fcvm.2021.688513 label-free and non-destructive imaging to obtain quantitative, optical biomarkers that have been shown to correlate with key events during CAVD progression. MPM can also be used to obtain spatiotemporal readouts of metabolic changes that occur in the cells. While cellular metabolism has been extensively explored for various cardiovascular disorders like atherosclerosis, hypertension, and heart failure, and has shown potential in elucidating key pathophysiological processes in heart valve diseases, it has yet to gain traction in the study of CAVD. Furthermore, MPM also provides structural, functional, and metabolic readouts that have the potential to correlate with key pathophysiological events in CAVD progression. This review outlines the applicability of MPM and its derived quantitative metrics for the detection and monitoring of early CAVD progression. The review will further focus on the MPM-detectable metabolic biomarkers that correlate with key biological events during valve pathogenesis and their potential role in assessing CAVD pathophysiology.

Keywords: calcific aortic valve disease, multiphoton microscopy, valve interstitial cell metabolism, aortic stenosis, early diagnosis

\section{INTRODUCTION}

Calcific aortic valve disease (CAVD) is the most common heart valve disease, with a prevalence of $25 \%$ in those 65 years and above (1). Additionally, 75\% patients with congenital bicuspid aortic valve disease develop CAVD by the age of 30 years $(2,3)$. CAVD is a progressive disease with complex pathophysiology (4), and is associated with a 50\% elevated risk of fatal cardiovascular pathologies resulting in more than 15,000 deaths annually in North America alone (5). The only available standard of care is valve replacement surgery (6), as early detection, prevention, and mitigation strategies are underdeveloped (7). Several techniques such as echocardiography, cardiac magnetic resonance imaging, and computed tomography are clinically employed for the diagnosis and monitoring of CAVD $(8,9)$, while newer techniques such as positron emission tomography are 
gaining traction (9). However, there remains a need for a multimodal technique capable of performing early detection and monitoring of CAVD progression.

Multiphoton microscopy (MPM) is well-suited to provide non-invasive assessments of tissue structure and function. The most commonly used MPM technique, two-photon excited fluorescence (TPEF) microscopy, employs the use of two photons of near-infrared (NIR) wavelengths to excite fluorophores, which offers advantages such as intrinsic depth sectioning, less photobleaching, and label-free imaging of various endogenous fluorophores (10-13). These characteristics make TPEF suitable for non-destructive, non-invasive, spatiotemporal imaging of live cells and tissue samples, both in vitro and in vivo (10, 12, 13). MPM has been shown to be useful for generating highresolution image-based data but also quantitative metrics that can be correlated with biologically-relevant features and events ranging from sub-cellular scales up to gross tissue morphology $(10,13-18)$.

TPEF allows for quantification of the endogenous fluorescence of the cellular co-factors flavin adenine dinucleotide (FAD) and the reduced forms of nicotinamide adenine dinucleotide (NADH) and nicotinamide adenine dinucleotide phosphate (NADPH). NAD(P)H and FAD play key roles as electron carriers in various metabolic pathways, including glycolysis, the tricarboxylic acid cycle, and the electron transport chain in mitochondria (11, 12, 19, 20). The ratio of the fluorescence intensity of these factors [e.g., $\mathrm{FAD} /(\mathrm{FAD}+\mathrm{NAD}(\mathrm{P}) \mathrm{H})]$, called optical redox ratio (ORR), can reveal insights into the interplay between glucose catabolism and oxidative phosphorylation $(11,12,19-21)$. NAD $(\mathrm{P}) \mathrm{H}$ autofluorescence can also be used to assess the mitochondrial organization via the mitochondrial fractal dimension (FD) parameter $(20,22,23)$.

In addition to spatially-resolved fluorescence measurements of $\mathrm{NAD}(\mathrm{P}) \mathrm{H}$, measurements of the time between excitation and emission can provide additional insights into cell metabolism through fluorescence lifetime imaging (FLIM). This technique involves estimating the fluorescence lifetime decay rates, which are sensitive to microenvironmental changes such as $\mathrm{pH}$ or protein binding (11). Of note, FLIM of NAD(P)H can be used to distinguish its bound and free states through a biexponential least-squares fit of the lifetime decay curves (11, 19, 24-26). Free $\mathrm{NAD}(\mathrm{P}) \mathrm{H}$ has a mean lifetime of $0.3-0.4 \mathrm{~ns}$, while protein-bound $\mathrm{NAD}(\mathrm{P}) \mathrm{H}$ has a mean lifetime of 1.9-5.7 ns (11). The proportion of free $\mathrm{NAD}(\mathrm{P}) \mathrm{H}$ tends to increase when cells are undergoing glycolysis, while bound $\mathrm{NAD}(\mathrm{P}) \mathrm{H}$ often increases with increases in the rate of oxidative phosphorylation. FLIM is advantageous because it is independent of fluorophore concentration, laser

Abbreviations: CARS, Coherent anti-Stokes Raman Spectroscopy; CAVD, Calcific Aortic Valve Disease; EVs, Extracellular Vesicles; FAD, Flavin Adenine Dinucleotide; FD, Fractal Dimension; FLIM, Fluorescence lifetime imaging; hMSCs, Human mesenchymal stem cells; MPM, Multiphoton Microscopy; NAD(P)H, Nicotinamide Adenine (phosphorylated) Dinucleotide Reduced; ORR, Optical Redox Ratio; ROS, Reactive Oxygen Species; SHG, Second Harmonic Generation; TPEF, Two-Photon Excited Fluorescence; VICs, Valve Interstitial Cells. intensity fluctuations, and the effects of tissue adsorption and scattering $(18,19,24-27)$.

Second harmonic generation (SHG) imaging is another powerful MPM technique used to assess non-centrosymmetric molecules like fibrillary collagen $(17,28-30)$. SHG is sensitive to collagen fiber amount, length, diameter, density, and orientation (31-33) and has been used in various research applications including dermatology, oncology, neurology, and cardiovascular disorders (17, 28-34). Apart from measuring collagen via SHG, TPEF imaging has been used to assess elastic fiber content, density, and length to characterize cardiovascular pathophysiology (17, 30, 35). MPM-based coherent Raman imaging techniques, such as coherent anti-Stokes Raman spectroscopy (CARS), have also provided a powerful tool to visualize lipid droplet organization, concentration, and size (2426, 29, 36-38). SHG and CARS imaging of collagen, calcium, and lipids can be performed simultaneously with TPEF microscopy $(11,13,20,39,40)$ and could be potentially used to characterize optical signatures associated with CAVD progression.

There are relatively few studies that have applied MPM for the study of aortic valves and its pathophysiology. MPM-based approaches combining TPEF, SHG and CARS, for label-free imaging of an aortic valve have been previously demonstrated (41). TPEF has been used to assess aortic valve interstitial cell (VIC) proliferation $(21,42)$, osteogenesis (43), and valve calcification in vitro and ex vivo (39). TPEF autofluorescence ratios have shown potential in assessing CAVD progression ex vivo (44). SHG has also been used to quantify collagen remodeling in valve tissues (45). This review outlines how labelfree MPM metrics have been employed to assess key events of CAVD progression, in valvular and non-valvular cells, tissues, and disease models. We then summarize the challenges and future directions for MPM as a tool to study valve disease.

\section{MPM-BASED DETECTION OF MARKERS FOR VALVE DISEASE IN OTHER PATHOLOGIES}

Multiple events contribute to CAVD progression. Some known hallmarks or markers of CAVD include endothelial damage, endothelial-to-mesenchymal transformation, oxidative stress, lipid deposition and oxidation, inflammation, collagen remodeling, and mineralization (4-7, 46-48). Multiple studies have employed label-free MPM techniques and metrics to assess similar events and biomarkers in other diseases and models as discussed below.

\section{Monitoring of Inflammation and Reactive Oxygen Species}

Multiple studies as described here have employed multimodal MPM approach by combining CARS, TPEF, and SHG to assess inflammation. $\mathrm{NAD}(\mathrm{P}) \mathrm{H}$ imaging via $\mathrm{TPEF}$ has been shown to be useful in identifying macrophages and CARS has been used to detect foam cells during spinal cord injury (38, 49, 50). MPM has also been used to assess inflammation in blood vessels to identify morphological differences between healthy 
and tumor tissues, lymphocytes, collagen fiber bundles, and endothelial damage $(51,52)$. Reactive oxygen species (ROS) are a primary cause of endothelial damage and tissue injury leading to inflammatory diseases (53), and are key modulators of cell metabolism (54). Correlation between cell metabolism and ROS has been well-characterized in cancers (55). Given ROS-mediated inflammation and lipid oxidation are key drivers of early CAVD initiation (56-58), imaging metabolic and morphological changes of cells as well as oxidized lipids via MPM to infer inflammation $(24,59)$, may serve as a powerful early detection tool to detect CAVD initiation.

\section{Monitoring of Extracellular Vesicles and Apoptotic Calcification}

Immune signaling, apoptosis, and $\mathrm{Ca}^{2+}$ ion flux are closely associated with mitochondrial dysfunction and CAVD progression (60). Apoptotic VICs have been shown to present ectonucleotide pyrophosphatase/phosphodiesterase-1 (eNPP1)containing extracellular vesicles (EVs) on their cell membrane, where these EVs are thought to promote mineralization (61). Recently, label-free FLIM has been utilized to image EVs isolated from macrophages and cancer cells (62). NAD(P)H lifetime determined by FLIM has also been used to assess apoptosis and shown to change before cleaved caspase-3 activation and mitochondrial dysfunction $(27,63)$. These results suggest a potential avenue for using FLIM to characterize apoptosis, and therefore EV-mediated dystrophic mineralization during CAVD progression.

\section{Monitoring of Extracellular Matrix Structure and Phenotypic Differentiation}

MPM has been used to monitor the osteogenic, adipogenic and chondrogenic differentiation of human mesenchymal stem cells (hMSCs) using various MPM-based metrics, including ORR, mitochondrial organization within the cell, collagen SHG, and FLIM of $\mathrm{NAD}(\mathrm{P}) \mathrm{H}$ and FAD $(19,20,64)$. These studies suggest that the assessment of the heterogeneity of the cell population, their capability for collagen synthesis and remodeling, and variation in their differential potential can be assessed via MPM techniques $(20,64,65)$. Considering the utility of TPEF and CARS to detect adipogenic differentiation of hMSCs and assess lipid amount, organization, orientation, and concentration $(20,25,26,36,64)$, MPM-based imaging of lipid deposition may be useful in monitoring CAVD progression. MPM imaging has already been used to visualize elastin and collagen microstructures in heart valves using TPEF and SHG, respectively $(17,30,45,66)$.

\section{MPM IN AORTIC VALVE PATHOLOGY AND PHYSIOLOGY}

\section{Ex vivo Characterization of Calcification}

TPEF autofluorescence at $800 \mathrm{~nm}$ excitation and 460 and $525 \mathrm{~nm}$ emission was associated with mineralization in $\mathrm{ApoE}^{-/-}$mice, calcified human valves, and calcific nodules generated in vitro, using a ratiometric approach, a result also corroborated by
CARS imaging (39). While the fluorescence emission at $525 \mathrm{~nm}$ was associated with mineralization, spectral analysis revealed that fluorescence emission at $460 \mathrm{~nm}$ was associated with collagen (39).

Recently, we have evaluated multiple ratios of autofluorescence intensity at various stages of disease in a mouse model of CAVD (44). In that study, autofluorescence intensities at specific two-photon excitation and emission wavelengths, represented as $\mathrm{A}_{\text {excitation/emission, were considered, }}$ including $A_{810 / 525}, A_{810 / 460}, A_{860 / 525}$, and $A_{755 / 460}$. We found that the $\left[\mathrm{A}_{860 / 525} /\left(\mathrm{A}_{755 / 460}+\mathrm{A}_{860 / 525}\right)\right]$ autofluorescence ratio rather than $\left[A_{810 / 525} /\left(A_{810 / 460}+A_{810 / 525}\right)\right]$ was more sensitive to CAVD progression (44). These TPEF autofluorescence ratios correlated negatively with proliferation, osteogenic differentiation, collagen remodeling, and calcium deposition. Indeed, reduced autofluorescence ratio at 16 weeks served as a predictor for increased calcification in the valve at 28 weeks (44). In another study, assessment of collagen remodeling via SHG revealed that during CAVD, collagen fibers in the spongiosa layer increased in number, width, and density while collagen fibers of the fibrosa became relatively shorter (45) (Figures 1A,B). SHG imaging also revealed decreased collagen amount and altered fiber alignment in different regions of aortic valve leaflets in an $\mathrm{ApoE}^{-/}$mice based CAVD model (66). In the same study, lipid droplets (Figure 1C) and cholesterol crystals were identified within cells (Figure 1D) and plaques (Figure 1E) in aortic valve leaflets via CARS imaging (66).

\section{In vitro Characterization of VIC Pathophysiology}

Our lab has previously reported that when VICs underwent a pathogenic phenotype shift, they experienced a decrease in ORR, suggesting a possible link between VIC pathology and its metabolic state $(21,42,43,67)$. TPEF imaging of VICs under quiescent and osteogenic conditions revealed that the ORR decreased during early osteogenic differentiation (Figure 1F) and correlated with gene expression of osteogenic markers. However, FD, a marker inversely proportional to mitochondrial clustering, increased at later time points and correlated with gene expression of osteogenic and structural markers as assessed by qRT-PCR. FD also correlated with nuclear morphology which was assessed via TPEF fluorescence maps (43). In another study, VICs subjected to conditions mimicking hypertensive pressures exhibited decreased ORR (21). Even in a more valve mimetic three-dimensional environment with physiological and pathological stretch, VIC ORR correlated negatively with proliferation (42). These studies demonstrate the in vitro utility of TPEF in assessing VIC structure, function, and phenotype during CAVD progression.

\section{BIOLOGICAL RELEVANCE OF MPM-BASED METRICS TO VALVE DISEASE}

During disease, stress, differentiation, or other pathophysiological conditions, cells undergo increased 


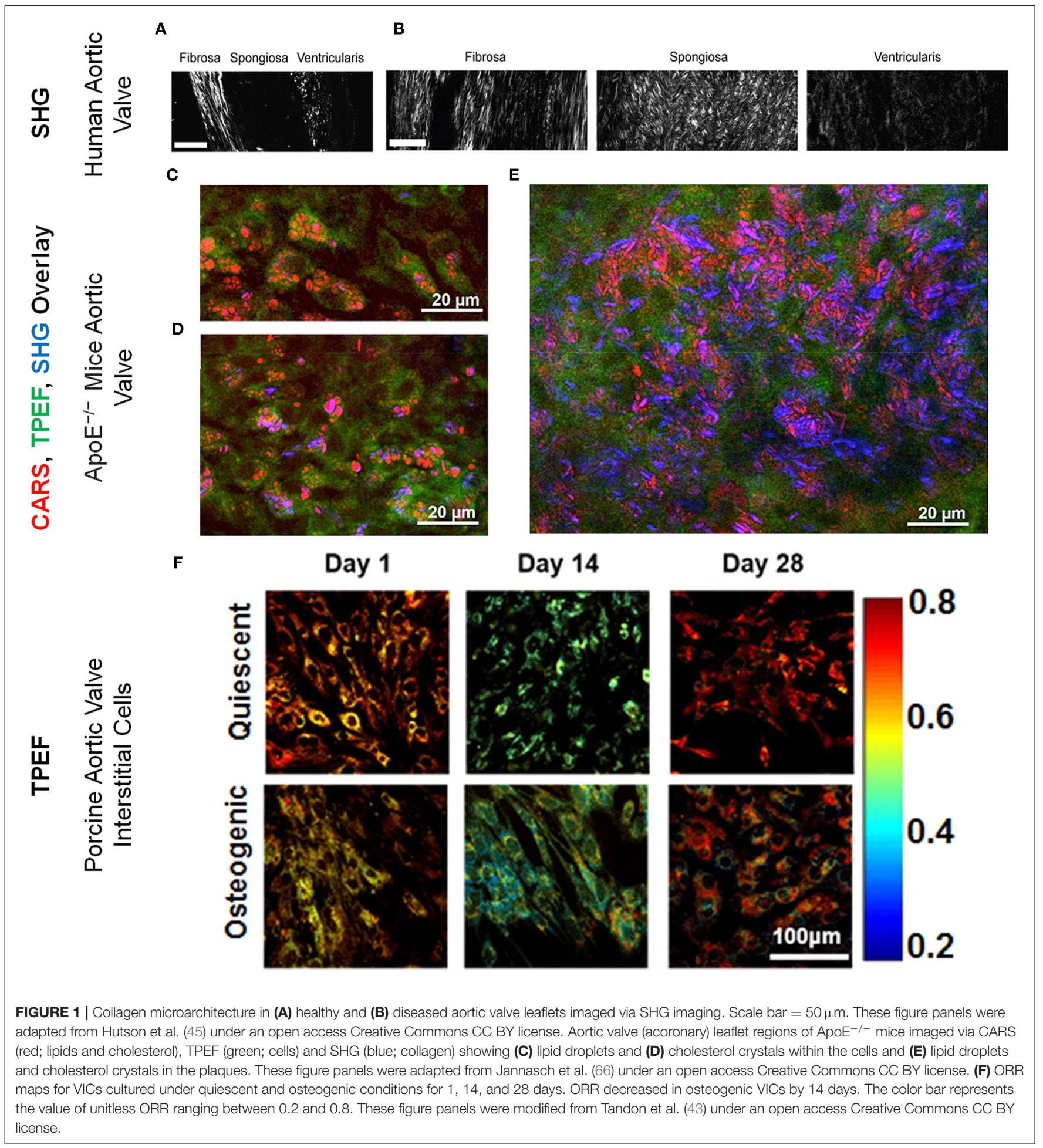

glycolysis resulting in increased production of $\mathrm{NAD}(\mathrm{P}) \mathrm{H}$ $(11,14,20)$. Under physiological conditions, it has been observed that cells are preferential to the process of oxidative phosphorylation for meeting their energy demands, which results in an increase in NAD+ concentrations $(11,14,20)$.
This ratio of NAD+ and NADH is correlated with the ratio of FAD and $\mathrm{NADH}$ autofluorescence as measured by ORR $(11,20)$. NAD $(\mathrm{P}) \mathrm{H}$ fluorescence can also be used to assess mitochondrial organization, which has been associated with multiple cardiovascular disorders $(20,23,63,68-73)$. 


\section{Mitochondrial Organization in Calcified Valves}

Dynamin-related protein-1, a protein responsible for mitochondrial fission was upregulated in stenotic valves, inhibition of which attenuated calcification $(60,74)$. Mitochondrial fission is known to induce autophagy (75), and inhibiting fission reduced mitochondrial clustering (72). Interestingly, osteogenic VICs showed higher FD implying less mitochondrial clustering as assessed by TPEF imaging of $\mathrm{NAD}(\mathrm{P}) \mathrm{H}$ fluorescence (43) but the specific functional role of mitochondrial clustering in valve pathophysiology is yet to be elucidated.

\section{CAVD Metabolic Profiling via Multi-Omics Approach}

The role of cellular metabolism has been widely explored in various cardiovascular disorders $(71,73,76,77)$ and metabolic regulators like osteocalcin, pyruvate dehydrogenase kinase, and adenosine monophosphate-activated protein kinase pathway have been implicated (78-81). These factors and pathways are known to be differentially regulated in diseased aortic valves (8284). In turn, aortic stenosis has been a known modulator of cardiac metabolism (85). Few studies exist that directly aimed at understanding metabolic changes and their role in CAVD progression $(21,42,43,67)$, while others employed proteomics and found differentially regulated metabolism-related proteins and/or protein clusters associated with aortic valve disease (8690). Researchers have also employed transcriptomics $(83,91)$ and multi-omics (92) approaches and revealed differentially expressed factors, which affect cellular metabolism during aortic valve disease.

\section{Metabolic Changes During VIC Pathophysiology}

VIC and hMSC osteogenic differentiation showcased similar trends with respect to ORR and FD $(20,43)$, an observation supported by the recently elucidated stemness characteristics of VICs (65). A glycolytic shift of metabolism during osteogenic differentiation has been speculated to occur due to the increased biosynthetic demand for collagen synthesis and remodeling $(20,67)$. However, other factors like pyruvate availability in media may also determine the tendency of cells to prefer glycolysis vs. oxidative phosphorylation $(19,20,64)$. In our in vitro study, increased proliferation associated with decreased ORR in VICs was regulated by the Akt/mTOR signaling pathway (42), which has also been observed in other studies $(55,93)$. These signaling pathways were also involved in the regulation of ROS-mediated oxidative stress and its effects on cell metabolism and proliferation (54). Reduced ORR suggested increased glycolysis and/or reduced oxidative phosphorylation during VIC proliferation and osteogenesis (11, 20, 42, 43). Indeed, VICs undergoing mineralization were enriched in proteins responsible for maintaining glycolysis and mediators for phosphate metabolism (94). Additionally, peripheral blood gene signatures associated with CAVD revealed increased proliferation and reduced oxidative phosphorylation (95). Additionally,
ATPase, an enzyme important for oxidative phosphorylation, was found to be downregulated in stenotic valves (83). Differences observed in the substrate utilization and glycolytic shifts in cardiovascular development and disorders $(77,85)$, and the extensive MPM-based assessment of hMSCs $(19,20,64)$, should inspire further exploration of metabolic imaging in VICs.

Cause-effect relationships between metabolic alterations and VIC pathophysiology and their correlation with disease require further inquiry. On that front, mechanisms, regulators, and diagnostic strategies for vascular inflammation and calcification are at a more advanced stage of being assessed via imaging techniques $(59,79,80,96,97)$, and efforts to incorporate these associations with valvular calcification may help to get a better understanding of metabolic imaging in CAVD. Further understanding of how metabolic regulators affect MPM metrics with respect to disease stage and severity, in the context of the aortic valve, is required to fully understand the extent of the biological relevance of MPM metrics in the context of CAVD.

\section{CHALLENGES ASSOCIATED WITH CLINICAL TRANSLATION AND FUTURE DIRECTIONS}

Despite several advantages, MPM is not devoid of associated limitations. Challenges exist in terms of specificity and resolution for a given fluorophore, dependency of depth penetration on the absorbing and scattering fluorophores, and minimal but existent photobleaching $(11,98)$. Some of the challenges associated with heart valve imaging are summarized below.

Intrinsic sources of contrast from $\mathrm{NAD}(\mathrm{P}) \mathrm{H}, \mathrm{FAD}$, lipids, collagen, elastin, and mineralization can facilitate MPMbased imaging of CAVD progression $(11,39)$. However, their overlapping spectra within the visible range can pose challenges in relating measurements to a specific source of contrast $(39,40)$. Unmixing the fluorescence spectra of each of the aforementioned components within the valve will be important in understanding how these optical signatures relate to disease stage and severity. Additional studies are needed for rigorous in vitro and $e x$ vivo screening of optical signatures correlated with each CAVD hallmark, including but not restricted to endothelial damage, infiltration of inflammatory cytokines, oxidization of lipids, apoptosis, and collagen remodeling. It should be noted that while some ex vivo characterization has been performed $(39,44,45)$, in vivo analysis is yet to be realized.

MPM-based intravital imaging of the ventricular wall has been performed $(15,16,99,100)$; however, in vivo imaging of valves faces challenges due to accessibility, tissue movement, and blood flow (28, 97, 101-104). Limitations of tissue accessibility are being addressed by enhancing flexibility and miniaturization of microendoscopy tools, which will help facilitate preclinical and clinical translation of MPM $(28,101-$ $103,105)$. Work is also focused on developing strategies to overcome motion-based artifacts introduced by heartbeat or physiological geometry changes (104). Additionally, researchers have developed algorithms to account for the NIR signal attenuation by blood (97). Indeed, there remain several 
TABLE 1 | Summary of label-free MPM techniques and metrics associated with CAVD progression.

\begin{tabular}{|c|c|c|c|}
\hline CAVD stage & CAVD event & \multicolumn{2}{|c|}{ MPM techniques and metabolic metrics } \\
\hline & Macrophages & - & $\begin{array}{l}\text { TPEF (presumably FAD and Lipofuscin, Em: 500-550 nm) } \\
\text { (50), Lipid-laden Macrophages - CARS (52) }\end{array}$ \\
\hline & Oxidative stress & - & $\begin{array}{l}\text { FLIM (Ex: }<760 \mathrm{~nm} \text {, Em: } 440-470 \mathrm{~nm}) \text { (Long lifetime species } \\
\text { in oxidized lipids) and CARS }(24,120)\end{array}$ \\
\hline \multirow[t]{5}{*}{$\begin{array}{l}\text { Progression (VIC } \\
\text { dedifferentiation, } \\
\text { Fibrosis, Calcification) }\end{array}$} & Apoptosis & - & $\begin{array}{l}\text { Neurons and astrocytes-TPEF (ORR increased) (11), FLIM } \\
\text { (Ex: <760 nm, Em: } 440-470 \mathrm{~nm} \text {; Increase or decrease of } \\
\text { NAD(P)H lifetime dependent on cell type) }(11,27,63)\end{array}$ \\
\hline & Proliferation & TPEF (ORR decreased) $(21,42-44)$ & $\begin{array}{l}\text { TPEF (ORR decreased) and FLIM (Ex: <760 nm, Em: } \\
440-470 \mathrm{~nm} \text {; NAD(P)H lifetime decreased) }(11,14)\end{array}$ \\
\hline & VIC dedifferentiation & $\begin{array}{l}\text { TPEF (ORR decreased early, FD increased } \\
\text { later time points) }(43,44)\end{array}$ & N/A \\
\hline & $\begin{array}{l}\text { Extracellular matrix } \\
\text { remodeling }\end{array}$ & $\begin{array}{l}\text { Collagen-SHG (Ex: } 890 \mathrm{~nm} \text {, Em: } \\
\text { 425-465 nm), Elastin-TPEF (Ex: } 760 \mathrm{~nm} \text {, } \\
\text { Em: } 420-460 \text { nm), (17, 30, 45, 66) }\end{array}$ & TPEF and SHG $(25,34,52,105,119)$ \\
\hline & Calcification & $\begin{array}{l}\text { Mineralization-TPEF (Ex: } 800 \mathrm{~nm} \text {, Em: } \\
460 \text { and } 525 \mathrm{~nm} \text { ), and CARS (39) }\end{array}$ & - \\
\hline
\end{tabular}

challenges before MPM-based techniques can be applied to the valve leaflets in vivo.

Recent advances in FLIM and CARS-based imaging of lipid bilayers, oxidized lipids, extracellular vesicles, and oxidative stress $(24,37,62)$ have opened new avenues for exploring label-free signatures in CAVD. Lipid infiltration, oxidation, and biosynthesis are associated with CAVD initiation and progression $(106,107)$, in addition to being key regulators of metabolism $(11,20)$. Furthermore, hypoxia-mediated collagen remodeling and cell metabolism in CAVD $(11,108-110)$, can also potentially be assessed by MPM imaging $(17,30,45,66)$. MPM may also prove useful in further assessing the correlation between metabolism and mineralization by imaging cellular metabolism of VICs, EVs, and mineralization of apoptotic bodies $(60,61$, 111). Understanding metabolic changes and their mechanisms during heart valve pathophysiology, may therefore open new avenues for therapeutic interventions as well, as it has in other cardiovascular disorders such as heart failure, hypertrophy, and arterial inflammation $(71,73,76,77)$.

\section{CONCLUSION}

MPM offers distinct advantages such as label-free detection, quantitative measurements, reduced phototoxicity, and increased depth penetration (10-13) relative to confocal microscopy. While multiple different techniques and biochemical assays have been utilized to assess CAVD progression, most techniques require the use of exogenous labels and dyes, cellular fixation, and lysis which restrict the longitudinal monitoring of live cells and tissues, unlike MPM based imaging (58, 112, 113). MPM offers a label-free non-destructive alternative that will allow conservation of the sample, time, and resources yet providing quantitative data along with spatial mapping of these biomarkers (10, 11, 13, 25, 34). MPM-based metrics have been widely employed in cancer research $(18,114-116)$, stem cell research $(19,20,64,93)$, wound healing studies $(14,29,114,117)$, other cardiovascular disorders $(35,97,118,119)$ (Table 1) and have been explored for clinical translation as well $(29,115$, $121,122)$. While MPM-based optical signatures and quantitative metrics may hold potential in streamlining in vitro and ex vivo CAVD detection and monitoring (Table 1), much work is required in elucidating distinct optical signatures that correlate with individual disease markers. Additionally, understanding the biological relevance of these biomarkers and their associated regulators is equally important in furthering the therapeutics and diagnostics of CAVD, a disease with no drug-based therapies, or early diagnostic tests (4-7). Advancements in probe design for accessibility and challenges associated with imaging moving objects with multiple confounding autofluorescent and absorbing sources must be overcome for the successful adoption of MPM techniques and metrics for clinical imaging of aortic valves $(28,97,101-105)$. 


\section{AUTHOR CONTRIBUTIONS}

IT and $\mathrm{KB}$ conceptualized the manuscript. IT, KPQ, and $\mathrm{KB}$ co-wrote the manuscript. All authors approved the submitted version of the article.

\section{REFERENCES}

1. Kodali SK, Velagapudi P, Hahn RT, Abbott D, Leon MB. Valvular heart disease in patients $\geq 80$ years of age. J Am Coll Cardiol. (2018) 71:2058-72. doi: 10.1016/j.jacc.2018.03.459

2. Yutzey KE, Demer LL, Body SC, Huggins GS, Towler DA, Giachelli CM, et al. Calcific aortic valve disease. Arteriosc Thromb Vasc Biol. (2014) 34:2387-93. doi: 10.1161/ATVBAHA.114.302523

3. Mordi I, Tzemos N. Bicuspid aortic valve disease: a comprehensive review. Cardiol Res Pract. (2012) 2012:196037. doi: 10.1155/2012/196037

4. Freeman RV, Otto CM. Spectrum of calcific aortic valve disease: pathogenesis, disease progression, and treatment strategies. Circulation. (2005) 111:3316-26. doi: 10.1161/CIRCULATIONAHA.104.486738

5. Roger VL, Go AS, Lloyd-Jones DM, Benjamin EJ, Berry JD, Borden WB, et al. Heart disease and stroke statistics-2012 update: a report from the American Heart Association. Circulation. (2012) 125:e2-e220. doi: 10.1161/CIR.0b013e31823ac046

6. Lerman DA, Prasad S, Alotti N. Calcific aortic valve disease: molecular mechanisms and therapeutic approaches. Eur Cardiol. (2015) 10:108-12. doi: 10.15420/ecr.2015.10.2.108

7. Maganti K, Rigolin VH, Sarano ME, Bonow RO. Valvular heart disease: diagnosis and management. Mayo Clinic Proc. (2010) 85:483-500. doi: $10.4065 / \mathrm{mcp} .2009 .0706$

8. Izquierdo-Gómez MM, Hernández-Betancor I, García-Niebla J, Marí-López B, Laynez-Cerdeña I, Lacalzada-Almeida J. Valve calcification in aortic stenosis: etiology and diagnostic imaging techniques. Biomed Res Int. (2017) 2017:5178631. doi: 10.1155/2017/5178631

9. Everett RJ, Newby DE, Jabbour A, Fayad ZA, Dweck MR. The role of imaging in aortic valve disease. Curr Cardiovasc Imaging Rep. (2016) 9:21. doi: $10.1007 / \mathrm{s} 12410-016-9383-\mathrm{z}$

10. Larson AM. Multiphoton microscopy. Nat Photonics. (2011) 5:1. doi: 10.1038/nphoton.an.2010.2

11. Kolenc OI, Quinn KP. Evaluating cell metabolism through autofluorescence imaging of NAD(P)H and FAD. Antioxid Redox Signal. (2017) 30:875-89. doi: 10.1089/ars.2017.7451

12. Bartolome F, Abramov AY. Measurement of mitochondrial NADH and FAD autofluorescence in live cells. Methods Mol Biol. (2015) 1264:263-70. doi: 10.1007/978-1-4939-2257-4_23

13. Zipfel WR, Williams RM, Webb WW. Nonlinear magic: multiphoton microscopy in the biosciences. Nat Biotechnol. (2003) 21:1369-77. doi: $10.1038 /$ nbt899

14. Jones JD, Ramser HE, Woessner AE, Quinn KP. In vivo multiphoton microscopy detects longitudinal metabolic changes associated with delayed skin wound healing. Commun Biol. (2018) 1:198. doi: 10.1038/s42003-018-0206-4

15. Jones JS, Small DM, Nishimura N. In vivo calcium imaging of cardiomyocytes in the beating mouse heart with multiphoton microscopy. Front Physiol. (2018) 9:969. doi: 10.3389/fphys.2018.00969

16. Li W, Nava RG, Bribriesco AC, Zinselmeyer BH, Spahn JH, Gelman AE, et al. Intravital 2-photon imaging of leukocyte trafficking in beating heart. J Clin Invest. (2012) 122:2499-508. doi: 10.1172/JCI62970

17. Schenke-Layland K. Non-invasive multiphoton imaging of extracellular matrix structures. J Biophotonics. (2008) 1:451-62. doi: 10.1002/jbio.200810045

18. Skala MC, Riching KM, Gendron-Fitzpatrick A, Eickhoff J, Eliceiri $\mathrm{KW}$, White JG, et al. In vivo multiphoton microscopy of $\mathrm{NADH}$ and FAD redox states, fluorescence lifetimes, and cellular morphology in precancerous epithelia. Proc Natl Acad Sci U S A. (2007) 104:19494-9. doi: $10.1073 /$ pnas.0708425104

\section{FUNDING}

This work was supported by the National Science Foundation [CMMI-1452943 to KB; CBET-1846853 to KPQ] and the American Heart Association [19PRE34370061 to IT].

19. Meleshina AV, Dudenkova VV, Bystrova AS, Kuznetsova DS, Shirmanova MV, Zagaynova EV. Two-photon FLIM of NAD(P)H and FAD in mesenchymal stem cells undergoing either osteogenic or chondrogenic differentiation. Stem Cell Res Ther. (2017) 8:15. doi: 10.1186/s13287-017-0484-7

20. Quinn KP, Sridharan GV, Hayden RS, Kaplan DL, Lee K, Georgakoudi I. Quantitative metabolic imaging using endogenous fluorescence to detect stem cell differentiation. Sci Rep. (2013) 3:3432. doi: 10.1038/srep03432

21. Lam NT, Muldoon TJ, Quinn KP, Rajaram N, Balachandran K. Valve interstitial cell contractile strength and metabolic state are dependent on its shape. Integr Biol (Camb). (2016) 8:1079-89. doi: 10.1039/C6IB00120C

22. Vargas I, Alhallak K, Kolenc OI, Jenkins SV, Griffin RJ, Dings RPM, et al. Rapid quantification of mitochondrial fractal dimension in individual cells. Biomed Opt Express. (2018) 9:5269-79. doi: 10.1364/BOE.9.005269

23. Xylas J, Varone A, Quinn KP, Pouli D, McLaughlin-Drubin ME, Thieu HT, et al. Noninvasive assessment of mitochondrial organization in threedimensional tissues reveals changes associated with cancer development. Int J Cancer. (2015) 136:322-32. doi: 10.1002/ijc.28992

24. Datta R, Alfonso-García A, Cinco R, Gratton E. Fluorescence lifetime imaging of endogenous biomarker of oxidative stress. Sci Rep. (2015) 5:9848. doi: $10.1038 /$ srep09848

25. Mazumder N, Balla NK, Zhuo G-Y, Kistenev YV, Kumar R, Kao F-J, et al. Label-free non-linear multimodal optical microscopy-basics, development, and applications. Front Phys. (2019) 7:170. doi: 10.3389/fphy.2019. 00170

26. Ranawat H, Pal S, Mazumder N. Recent trends in two-photon autofluorescence lifetime imaging (2P-FLIM) and its biomedical applications. Biomed Eng Lett. (2019) 9:293-310. doi: 10.1007/s13534-019-00119-7

27. Bower AJ, Marjanovic M, Zhao Y, Li J, Chaney EJ, Boppart SA. Label-free in vivo cellular-level detection and imaging of apoptosis. J Biophotonics. (2017) 10:143-50. doi: 10.1002/jbio.201600003

28. Garofalakis A, Kruglik SG, Mansuryan T, Gillibert A, Thiberville L, Louradour F, et al. Characterization of a multicore fiber image guide for nonlinear endoscopic imaging using two-photon fluorescence and second-harmonic generation. J Biomed Opt. (2019) 24:1-12. doi: 10.1117/1.JBO.24.10.106004

29. König K, Breunig HG, Batista A, Schindele A, Zieger M, Kaatz M. Translation of two-photon microscopy to the clinic: multimodal multiphoton CARS tomography of in vivo human skin. J Biomed Opt. (2020) 25:1-12. doi: 10.1117/1.JBO.25.1.014515

30. Schenke-Layland K, Stock UA, Nsair A, Xie J, Angelis E, Fonseca CG, et al. Cardiomyopathy is associated with structural remodelling of heart valve extracellular matrix. Eur Heart J. (2009) 30:2254-65. doi: 10.1093/eurheartj/ehp267

31. Quinn KP, Sullivan KE, Liu Z, Ballard Z, Siokatas C, Georgakoudi I, et al. Optical metrics of the extracellular matrix predict compositional and mechanical changes after myocardial infarction. Sci Rep. (2016) 6:35823. doi: $10.1038 /$ srep35823

32. Quinn KP, Georgakoudi I. Rapid quantification of pixel-wise fiber orientation data in micrographs. J Biomed Opt. (2013) 18:046003. doi: 10.1117/1.JBO.18.4.046003

33. Liu Z, Pouli D, Sood D, Sundarakrishnan A, Hui Mingalone CK, Arendt $\mathrm{LM}$, et al. Automated quantification of three-dimensional organization of fiber-like structures in biological tissues. Biomaterials. (2016) 116:34-47. doi: 10.1016/j.biomaterials.2016.11.041

34. Zipfel WR, Williams RM, Christie R, Nikitin AY, Hyman BT, Webb WW. Live tissue intrinsic emission microscopy using multiphoton-excited native fluorescence and second harmonic generation. Proc Natl Acad Sci U S A. (2003) 100:7075-80. doi: 10.1073/pnas.0832308100 
35. Megens R, Reitsma S, Schiffers P, Hilgers R, De Mey J, Slaaf D, et al. Twophoton microscopy of vital murine elastic and muscular arteries. J Vasc Res. (2006) 44:87-98. doi: 10.1159/000098259

36. Breunig HG, Bückle R, Kellner-Höfer M, Weinigel M, Lademann J, Sterry $\mathrm{W}$, et al. Combined in vivo multiphoton and CARS imaging of healthy and disease-affected human skin. Microsc Res Tech. (2012) 75:492-8. doi: $10.1002 /$ jemt.21082

37. Bradley J, Pope I, Wang Y, Langbein W, Borri P, Swann K. Dynamic label-free imaging of lipid droplets and their link to fatty acid and pyruvate oxidation in mouse eggs. J Cell Sci. (2019) 132:jcs228999. doi: 10.1242/jcs.228999

38. Tamosaityte S, Galli R, Uckermann O, Sitoci-Ficici KH, Koch M, Later $\mathrm{R}$, et al. Inflammation-related alterations of lipids after spinal cord injury revealed by Raman spectroscopy. J Biomed Opt. (2016) 21:61008. doi: 10.1117/1.JBO.21.6.061008

39. Baugh LM, Liu Z, Quinn KP, Osseiran S, Evans CL, Huggins GS, et al. Non-destructive two-photon excited fluorescence imaging identifies early nodules in calcific aortic-valve disease. Nat Biomedl Eng. (2017) 1:914-24. doi: 10.1038/s41551-017-0152-3

40. Croce AC, Bottiroli G. Autofluorescence spectroscopy and imaging: a tool for biomedical research and diagnosis. Eur J Histochem. (2014) 58:2461. doi: 10.4081/ejh.2014.2461

41. Büttner P, Galli R, Jannasch A, Schnabel C, Waldow T, Koch E. Heart valve stenosis in laser spotlights: insights into a complex disease. Clin Hemorheol Microcirc. (2014) 58:65-75. doi: 10.3233/CH-141882

42. Lam NT, Tandon I, Balachandran K. The role of fibroblast growth factor 1 and 2 on the pathological behavior of valve interstitial cells in a threedimensional mechanically-conditioned model. J Biol Eng. (2019) 13:45. doi: 10.1186/s13036-019-0168-1

43. Tandon I, Kolenc OI, Cross D, Vargas I, Johns S, Quinn KP, et al. Label-free metabolic biomarkers for assessing valve interstitial cell calcific progression. Sci Rep. (2020) 10:10317. doi: 10.1038/s41598-020-66960-4

44. Tandon I, Johns S, Woessner A, Perez J, Cross D, Ozkizilcik A, et al. Label-free optical biomarkers detect early calcific aortic valve disease in a wild-type mouse model. BMC Cardiovasc Disord. (2020) 20:521. doi: 10.1186/s12872-020-01776-8

45. Hutson HN, Marohl T, Anderson M, Eliceiri K, Campagnola P, Masters KS. Calcific aortic valve disease is associated with layer-specific alterations in collagen architecture. PLoS One. (2016) 11:e0163858. doi: 10.1371/journal.pone.0163858

46. Chester AH. Molecular and cellular mechanisms of valve calcification. Aswan Heart Centre Sci Pract Ser. (2011) 2011:4. doi: 10.5339/ahcsps.2011.4

47. Beckmann E, Grau JB, Sainger R, Poggio P, Ferrari G. Insights into the use of biomarkers in calcific aortic valve disease. J Heart Valve Dis. (2010) 19:441-52.

48. Leopold JA. Cellular mechanisms of aortic valve calcification. Circulation Cardiovascular interventions. (2012) 5:605-14. doi: 10.1161/CIRCINTERVENTIONS.112.971028

49. Galli R, Sitoci-Ficici KH, Uckermann O, Later R, Marečková M, Koch M, et al. Label-free multiphoton microscopy reveals relevant tissue changes induced by alginate hydrogel implantation in rat spinal cord injury. Sci Rep. (2018) 8:10841. doi: 10.1038/s41598-018-29140-Z

50. Uckermann O, Galli R, Beiermeister R, Sitoci-Ficici KH, Later R, Leipnitz $\mathrm{E}$, et al. Endogenous two-photon excited fluorescence provides label-free visualization of the inflammatory response in the rodent spinal cord. Biomed Res Int. (2015) 2015:859084. doi: 10.1155/2015/859084

51. Xi G, Cao N, Guo W, Kang D, Chen Z, He J, et al. Label-free imaging of blood vessels in human normal breast and breast tumor tissue using multiphoton microscopy. Scanning. (2019) 2019:5192875. doi: 10.1155/2019/5192875

52. Lim RS, Kratzer A, Barry NP, Miyazaki-Anzai S, Miyazaki M, Mantulin WW, et al. Multimodal CARS microscopy determination of the impact of diet on macrophage infiltration and lipid accumulation on plaque formation in ApoE-deficient mice. J Lipid Res. (2010) 51:1729-37. doi: 10.1194/jlr.M003616

53. Mittal M, Siddiqui MR, Tran K, Reddy SP, Malik AB. Reactive oxygen species in inflammation and tissue injury. Antioxid Redox Signal. (2014) 20:1126-67. doi: 10.1089/ars.2012.5149

54. Schieber M, Chandel NS. ROS function in redox signaling and oxidative stress. Curr Biol. (2014) 24:R453-R62. doi: 10.1016/j.cub.2014.03.034
55. Koundouros N, Poulogiannis G. Phosphoinositide 3-kinase/Akt signaling and redox metabolism in cancer. Front Oncol. (2018) 8:160. doi: $10.3389 /$ fonc. 2018.00160

56. Alushi B, Curini L, Christopher MR, Grubitzch H, Landmesser U, Amedei A, et al. Calcific aortic valve disease-natural history and future therapeutic strategies. Front Pharmacol. (2020) 11:685. doi: 10.3389/fphar.2020. 00685

57. Towler DA. Molecular and cellular aspects of calcific aortic valve disease. Circ Res. (2013) 113:198-208. doi: 10.1161/CIRCRESAHA.113.300155

58. Miller JD, Weiss RM, Heistad DD. Calcific aortic valve stenosis: methods, models, and mechanisms. Circ Res. (2011) 108:1392-412. doi: 10.1161/CIRCRESAHA.110.234138

59. Orndorff RL, Hong N, Yu K, Feinstein SI, Zern BJ, Fisher AB, et al. NOX2 in lung inflammation: quantum dot based in situ imaging of NOX2-mediated expression of vascular cell adhesion molecule-1. Am J Physiol Lung Cell Mol Physiol. (2014) 306:L260-L8. doi: 10.1152/ajplung.00278.2013

60. Pedriali G, Morciano G, Patergnani S, Cimaglia P, Morelli C, Mikus E, et al. Aortic valve stenosis and mitochondrial dysfunctions: clinical and molecular perspectives. Int J Mol Sci. (2020) 21:4899. doi: 10.3390/ijms21144899

61. Bouchareb R, Boulanger MC, Fournier D, Pibarot P, Messaddeq Y, Mathieu P. Mechanical strain induces the production of spheroid mineralized microparticles in the aortic valve through a RhoA/ROCKdependent mechanism. J Mol Cell Cardiol. (2014) 67:49-59. doi: 10.1016/j.yjmcc.2013.12.009

62. Sorrells JE, Martin EM, Aksamitiene E, Mukherjee P, Alex A, Chaney EJ, et al. Label-free characterization of single extracellular vesicles using twophoton fluorescence lifetime imaging microscopy of NAD(P)H. Sci Rep. (2021) 11:3308. doi: 10.1038/s41598-020-80813-0

63. Yu J-S, Guo H-W, Wang H-W, Wang C-H, Wei Y-H. Increase of reduced nicotinamide adenine dinucleotide fluorescence lifetime precedes mitochondrial dysfunction in staurosporine-induced apoptosis of HeLa cells. J Biomed Opt. (2011) 16:036008. doi: 10.1117/1.3560513

64. Rice WL, Kaplan DL, Georgakoudi I. Two-photon microscopy for noninvasive, quantitative monitoring of stem cell differentiation. PLoS One. (2010) 5:e10075. doi: 10.1371/journal.pone.0010075

65. Bogdanova M, Zabirnyk A, Malashicheva A, Enayati KZ, Karlsen TA, Kaljusto M-L, et al. Interstitial cells in calcified aortic valves have reduced differentiation potential and stem cell-like properties. Sci Rep. (2019) 9:12934. doi: 10.1038/s41598-019-49016-0

66. Jannasch A, Schnabel C, Galli R, Faak S, Büttner P, Dittfeld C, et al. Optical coherence tomography and multiphoton microscopy offer new options for the quantification of fibrotic aortic valve disease in $\mathrm{ApoE}^{-/-}$mice. Sci Rep. (2021) 11:5834. doi: 10.1038/s41598-021-85142-4

67. Kamel PI, Qu X, Geiszler AM, Nagrath D, Harmancey R, Taegtmeyer $\mathrm{H}$, et al. Metabolic regulation of collagen gel contraction by porcine aortic valvular interstitial cells. J R Soc Interface. (2014) 11:20140852. doi: 10.1098/rsif.2014.0852

68. Ong S-B, Hausenloy DJ. Mitochondrial morphology and cardiovascular disease. Cardiovasc Res. (2010) 88:16-29. doi: 10.1093/cvr/cvq237

69. Barlow $\mathrm{CH}$, Harden WR, 3rd, Harken AH, Simson MB, Haselgrove JC, Chance B, et al. Fluorescence mapping of mitochondrial redox changes in heart and brain. Crit Care Med. (1979) 7:402-6. doi: 10.1097/00003246-197909000-00011

70. Mayevsky A, Rogatsky GG. Mitochondrial function in vivo evaluated by NADH fluorescence: from animal models to human studies. Am J Physiol Cell Physiol. (2007) 292:C615-40. doi: 10.1152/ajpcell.00249.2006

71. Doenst T, Nguyen TD, Abel ED. Cardiac metabolism in heart failure: implications beyond ATP production. Circ Res. (2013) 113:709-24. doi: 10.1161/CIRCRESAHA.113.300376

72. Huang P, Yu T, Yoon Y. Mitochondrial clustering induced by overexpression of the mitochondrial fusion protein Mfn2 causes mitochondrial dysfunction and cell death. Eur J Cell Biol. (2007) 86:289-302. doi: 10.1016/j.ejcb.2007.04.002

73. Kolwicz SC, Purohit S, Tian R. Cardiac metabolism and its interactions with contraction, growth, and survival of cardiomyocytes. Circ Res. (2013) 113:603-16. doi: 10.1161/CIRCRESAHA.113.302095

74. Rogers MA, Maldonado N, Hutcheson JD, Goettsch C, Goto S, Yamada $\mathrm{I}$, et al. Dynamin-related protein 1 inhibition attenuates cardiovascular 
calcification in the presence of oxidative stress. Circ Res. (2017) 121:220-33. doi: 10.1161/CIRCRESAHA.116.310293

75. Westermann B. Bioenergetic role of mitochondrial fusion and fission. Biochim Biophys Acta. (2012) 1817:1833-8. doi: 10.1016/j.bbabio.2012.02.033

76. van der Velden J, Tocchetti CG, Varricchi G, Bianco A, Sequeira V, HilfikerKleiner D, et al. Metabolic changes in hypertrophic cardiomyopathies: scientific update from the Working Group of Myocardial Function of the European Society of Cardiology. Cardiovasc Res. (2018) 114:1273-80. doi: $10.1093 / \mathrm{cvr} / \mathrm{cvy} 147$

77. Gibb AA, Hill BG. Metabolic coordination of physiological and pathological cardiac remodeling. Circ Res. (2018) 123:107-28. doi: 10.1161/CIRCRESAHA.118.312017

78. Rashdan NA, Sim AM, Cui L, Phadwal K, Roberts FL, Carter R, et al. Osteocalcin regulates arterial calcification via altered wnt signaling and glucose metabolism. J Bone Miner Res. (2020) 35:357-67. doi: $10.1002 / j b m r .3888$

79. Demer LL, Tintut Y. Inflammatory, metabolic, and genetic mechanisms of vascular calcification. Arteriosc Thromb Vasc Biol. (2014) 34:715-23. doi: 10.1161/ATVBAHA.113.302070

80. Leem J, Lee IK. Mechanisms of vascular calcification: the pivotal role of pyruvate dehydrogenase kinase 4. Endocrinol Metab (Seoul). (2016) 31:5261. doi: 10.3803/EnM.2016.31.1.52

81. Crewe C, Schafer C, Lee I, Kinter M, Szweda LI. Regulation of pyruvate dehydrogenase kinase 4 in the heart through degradation by the lon protease in response to mitochondrial substrate availability. J Biol Chem. (2017) 292:305-12. doi: 10.1074/jbc.M116.754127

82. Chen J, Lin Y, Sun Z. Deficiency in the anti-aging gene Klotho promotes aortic valve fibrosis through AMPK $\alpha$-mediated activation of RUNX2. Aging Cell. (2016) 15:853-60. doi: 10.1111/acel.12494

83. Bossé Y, Miqdad A, Fournier D, Pépin A, Pibarot P, Mathieu P. Refining molecular pathways leading to calcific aortic valve stenosis by studying gene expression profile of normal and calcified stenotic human aortic valves. Circ Cardiovasc Genet. (2009) 2:489-98. doi: 10.1161/CIRCGENETICS.108.820795

84. Rajamannan NM, Subramaniam M, Rickard D, Stock SR, Donovan $\mathrm{J}$, Springett $\mathrm{M}$, et al. Human aortic valve calcification is associated with an osteoblast phenotype. Circulation. (2003) 107:2181-4. doi: 10.1161/01.CIR.0000070591.21548.69

85. Heather LC, Howell NJ, Emmanuel Y, Cole MA, Frenneaux MP, Pagano $\mathrm{D}$, et al. Changes in cardiac substrate transporters and metabolic proteins mirror the metabolic shift in patients with aortic stenosis. PLoS One. (2011) 6:e26326. doi: 10.1371/journal.pone.0026326

86. Martin-Rojas T, Mourino-Alvarez L, Alonso-Orgaz S, Rosello-Lleti E, Calvo E, Lopez-Almodovar LF, et al. iTRAQ proteomic analysis of extracellular matrix remodeling in aortic valve disease. Sci Rep. (2015) 5:17290. doi: $10.1038 /$ srep 17290

87. Mourino-Alvarez L, Baldan-Martin M, Sastre-Oliva T, Martin-Lorenzo M, Maroto AS, Corbacho-Alonso N, et al. A comprehensive study of calcific aortic stenosis: from rabbit to human samples. Dis Model Mech. (2018) 11:dmm033423. doi: $10.1242 / \mathrm{dmm} .033423$

88. Gil-Dones F, Martín-Rojas T, López-Almodovar LF, Juárez-Tosina R, de la Cuesta F, Álvarez-Llamas G, et al. Development of an optimal protocol for the proteomic analysis of stenotic and healthy aortic valves. Rev Esp Cardiol. (2010) 63:46-53. doi: 10.1016/S1885-5857(10)70008-6

89. Oda T, Matsumoto K-i. Proteomic analysis in cardiovascular research. Surg Today. (2016) 46:285-96. doi: 10.1007/s00595-015-1169-4

90. Weisell J, Ohukainen P, Näpänkangas J, Ohlmeier S, Bergmann U, Peltonen $\mathrm{T}$, et al. Heat shock protein 90 is downregulated in calcific aortic valve disease. BMC Cardiovasc Disord. (2019) 19:306. doi: 10.1186/s12872-01901294-2

91. Greene CL, Jaatinen KJ, Wang H, Koyano TK, Bilbao MS, Woo YJ. Transcriptional profiling of normal, stenotic, and regurgitant human aortic valves. Genes (Basel). (2020) 11:789. doi: 10.3390/genes11070789

92. Schlotter F, Halu A, Goto S, Blaser MC, Body SC, Lee LH, et al. Spatiotemporal multi-omics mapping generates a molecular atlas of the aortic valve and reveals networks driving disease. Circulation. (2018) 138:377-93. doi: 10.1161/CIRCULATIONAHA.117.032291
93. Yu JSL, Cui W. Proliferation, survival and metabolism: the role of PI3K/AKT/mTOR signalling in pluripotency and cell fate determination. Development. (2016) 143:3050-60. doi: 10.1242/dev.137075

94. Khan K, Yu B, Kiwan C, Shalal Y, Filimon S, Cipro M, et al. The role of $\mathrm{Wnt} / \beta$-catenin pathway mediators in aortic valve stenosis. Front Cell Dev Biol. (2020) 8:862. doi: 10.3389/fcell.2020.00862

95. MacGrogan D, Martínez-Poveda B, Desvignes J-P, Fernandez-Friera L, Gomez MJ, Vilariño EG, et al. Identification of a peripheral blood gene signature predicting aortic valve calcification. Physiol Genomics. (2020) 52:563-74. doi: 10.1152/physiolgenomics.00034.2020

96. Hjortnaes J, Butcher J, Figueiredo J-L, Riccio M, Kohler RH, Kozloff $\mathrm{KM}$, et al. Arterial and aortic valve calcification inversely correlates with osteoporotic bone remodelling: a role for inflammation. Eur Heart J. (2010) 31:1975-84. doi: 10.1093/eurheartj/ehq237

97. Sheth RA, Tam JM, Maricevich MA, Josephson L, Mahmood U. Quantitative endovascular fluorescence-based molecular imaging through blood of arterial wall inflammation. Radiology. (2009) 251:813-21. doi: 10.1148/radiol.2513081450

98. Masters BR. Confocal Microscopy and Multiphoton Excitation Microscopy the Genesis of live Cell Imaging, Vol. PM161. Society of Photo-optical Instrumentation Engineers (2006). 230 p. Available online at: http://ezaccess. libraries.psu.edu/login?url=http://dx.doi.org/10.1117/3.660403

99. Matsuura R, Miyagawa S, Fukushima S, Goto T, Harada A, Shimozaki $\mathrm{Y}$, et al. Intravital imaging with two-photon microscopy reveals cellular dynamics in the ischeamia-reperfused rat heart. Sci Rep. (2018) 8:15991. doi: 10.1038/s41598-018-34295-w

100. Allan-Rahill NH, Lamont MRE, Chilian WM, Nishimura N, Small DM. Intravital microscopy of the beating murine heart to understand cardiac leukocyte dynamics. Front Immunol. (2020) 11:92. doi: $10.3389 /$ fimmu.2020.00092

101. Ducourthial G, Leclerc P, Mansuryan T, Fabert M, Brevier J, Habert R, et al. Development of a real-time flexible multiphoton microendoscope for labelfree imaging in a live animal. Sci Rep. (2015) 5:18303. doi: 10.1038/srep18303

102. Zhao Y, Sheng M, Huang L, Tang S. Design of a fiber-optic multiphoton microscopy handheld probe. Biomed Opt Express. (2016) 7:3425-37. doi: 10.1364/BOE.7.003425

103. König K, Weinigel M, Hoppert D, Bückle R, Schubert H, Köhler MJ, et al. Multiphoton tissue imaging using high-NA microendoscopes and flexible scan heads for clinical studies and small animal research. J Biophotonics. (2008) 1:506-13. doi: 10.1002/jbio.200810049

104. Soulet D, Lamontagne-Proulx J, Aubé B, Davalos D. Multiphoton intravital microscopy in small animals: motion artefact challenges and technical solutions. J Microsc. (2020) 278:3-17. doi: 10.1111/jmi.12880

105. Huang L, Zhou X, Liu Q, MacAulay CE, Tang S. Miniaturized multimodal multiphoton microscope for simultaneous two-photon and three-photon imaging with a dual-wavelength Er-doped fiber laser. Biomed Opt Express. (2020) 11:624-35. doi: 10.1364/BOE.381473

106. Chen HY, Cairns BJ, Small AM, Burr HA, Ambikkumar A, Martinsson A, et al. Association of FADS1/2 locus variants and polyunsaturated fatty acids with aortic stenosis. JAMA Cardiol. (2020) 5:694-702. doi: 10.1001/jamacardio.2020.0246

107. Peeters FECM, Meex SJR, Dweck MR, Aikawa E, Crijns HJGM, Schurgers LJ, et al. Calcific aortic valve stenosis: hard disease in the heart: a biomolecular approach towards diagnosis and treatment. Eur Heart J. (2017) 39:2618-24. doi: 10.1093/eurheartj/ehx653

108. Folco EJ, Sheikine Y, Rocha VZ, Christen T, Shvartz E, Sukhova GK, et al. Hypoxia but not inflammation augments glucose uptake in human macrophages: implications for imaging atherosclerosis with 18fluorinelabeled 2-deoxy-D-glucose positron emission tomography. J Am Coll Cardiol. (2011) 58:603-14. doi: 10.1016/j.jacc.2011.03.044

109. Sapp MC, Krishnamurthy VK, Puperi DS, Bhatnagar S, Fatora G, Mutyala N, et al. Differential cell-matrix responses in hypoxia-stimulated aortic versus mitral valves. J $R$ Soc Interface. (2016) 13:20160449. doi: 10.1098/rsif.2016.0449

110. Swaminathan G, Krishnamurthy VK, Sridhar S, Robson DC, Ning Y, Grande-Allen KJ. Hypoxia stimulates synthesis of neutrophil gelatinaseassociated lipocalin in aortic valve disease. Front Cardiovasc Med. (2019) 6:156. doi: $10.3389 /$ fcvm. 2019.00156 
111. Kutryb-Zajac B, Jablonska P, Serocki M, Bulinska A, Mierzejewska P, Friebe D, et al. Nucleotide ecto-enzyme metabolic pattern and spatial distribution in calcific aortic valve disease; its relation to pathological changes and clinical presentation. Clin Res Cardiol. (2020) 109:137-60. doi: 10.1007/s00392-019-01495-x

112. Rutkovskiy A, Malashicheva A, Sullivan G, Bogdanova M, Kostareva A, Stensløkken K-O, et al. Valve interstitial cells: the key to understanding the pathophysiology of heart valve calcification. J Am Heart Assoc. (2017) 6:e06339. doi: 10.1161/JAHA.117.006339

113. Small A, Kiss D, Giri J, Anwaruddin S, Siddiqi H, Guerraty $\mathrm{M}$, et al. Biomarkers of calcific aortic valve disease. Arteriosc Thromb Vasc Biol. (2017) 37:623-32. doi: 10.1161/ATVBAHA.116. 308615

114. Yew E, Rowlands C, So PTC. Application of multiphoton microscopy in dermatological studies: a mini-review. J Innov Opt Health Sci. (2014) 7:1330010. doi: 10.1142/S1793545813300103

115. Perry SW, Burke RM, Brown EB. Two-photon and second harmonic microscopy in clinical and translational cancer research. Ann Biomed Eng. (2012) 40:277-91. doi: 10.1007/s10439-0120512-9

116. Alhallak K, Rebello LG, Muldoon TJ, Quinn KP, Rajaram N. Optical redox ratio identifies metastatic potential-dependent changes in breast cancer cell metabolism. Biomed Opt Express. (2016) 7:4364-74. doi: 10.1364/BOE.7.004364

117. Jones JD, Ramser HE, Woessner AE, Veves A, Quinn KP. Quantifying agerelated changes in skin wound metabolism using in vivo multiphoton microscopy. Adv Wound Care (New Rochelle). (2020) 9:90-102. doi: 10.1089/wound.2019.1030
118. Scherschel JA, Rubart M. Cardiovascular imaging using twophoton microscopy. Microsc Microanal. (2008) 14:492-506. doi: $10.1017 /$ S1431927608080835

119. Wang HW, Le TT, Cheng JX. Label-free imaging of arterial cells and extracellular matrix using a multimodal CARS microscope. Opt Commun. (2008) 281:1813-22. doi: 10.1016/j.optcom.2007.07.067

120. Datta R, Heylman C, George SC, Gratton E. Label-free imaging of metabolism and oxidative stress in human induced pluripotent stem cell-derived cardiomyocytes. Biomed Opt Express. (2016) 7:1690-701. doi: 10.1364/BOE.7.001690

121. WANG B-G, KÖNIG K, HALBHUBER K-J. Two-photon microscopy of deep intravital tissues and its merits in clinical research. J Microsc. (2010) 238:1-20. doi: 10.1111/j.1365-2818.2009.03330.x

122. König K, Ehlers A, Riemann I, Schenkl S, Bückle R, Kaatz M. Clinical two-photon microendoscopy. Microsc Res Tech. (2007) 70:398-402. doi: $10.1002 /$ jemt. 20445

Conflict of Interest: The authors declare that the research was conducted in the absence of any commercial or financial relationships that could be construed as a potential conflict of interest.

Copyright $\odot 2021$ Tandon, Quinn and Balachandran. This is an open-access article distributed under the terms of the Creative Commons Attribution License (CC BY). The use, distribution or reproduction in other forums is permitted, provided the original author(s) and the copyright owner(s) are credited and that the original publication in this journal is cited, in accordance with accepted academic practice. No use, distribution or reproduction is permitted which does not comply with these terms. 